\title{
Research on the Relationship between Financial Insurance and the Real Economy Development
}

\author{
Chengcheng Zheng \\ School of Insurance and Economics, University of International Business and Economics, Beijing \\ 100029, China \\ zhengchengcheng7@126.com
}

\begin{abstract}
The real economy sector is a significant part of national economic development. It is a main channel for creating real wealth, realizing full employment, and promoting economic growth. However, in the current reality background of economic development "turning to virtual economy from the real economy", the real economy is faced with a series of "financing difficulties". Such being the case, on the basis of in-depth anatomy of the real economy development dilemma, regarding insurance funds as a long-term and large-scale capital stock can be promising for the real economy (especially small and medium-sized real economy manufacturing enterprises, in the field of providing risk guarantee and "blood transfusion" for the real economy in the capital market. Moreover, the thesis further analyzes the three major path dependence of insurance funds to promote real economic development, which provides a benchmark for the potential risk prevention in promoting the sound development of the real economy. Finally, the thesis proposes a series of recommendations for risk prevention.
\end{abstract}

Keywords: Financial insurance, real economy development, risk prevention.

\section{Introduction}

As an important part of modern finance, insurance is closely related to the development of the real economy. Insurance promotes economic development and social stability via its own deepening and functions of transferring risks, financial intermediary, and loss compensation. Meanwhile, its effect on economic growth is not limited to the function of social stabilizers. It can also become a booster of economic growth as well, booming the development of the real economy.

From the perspective of financial insurance, with the rapid development of the insurance market, insurance funds play an important and positive role in the operations of economy and finance, due to its long-term, large-scale, and stable-source characteristics. However, in recent years, the scale of financial insurance has become larger and larger, and the phenomenon of profit-driven has risen one after another. From 2015 to 2016, Baoneng made use of insurance funds and bank capital to become the first majority shareholder of the corporate champion of glass industry (China CSG Holding CO., Ltd) and real estate industry (China Vanke CO., Ltd). In addition, Baoneng is targeting the leading enterprises in the household appliance industry (Gree Electric).

In this way, the "sloshing around" of insurance funds in the capital market has set off a "carnage" in physical manufacturing enterprises. In fact, if financial capital enters a high-quality entity with banners, releasing its accumulated energy for many years, using its technology and brands to expand its products and line of business, it is rather easy to grow its performance when the industry environment is stale or rising. However, if the insurance capital rapidly sells the stock to earn profit and disrupts the operation of physical manufacturing enterprises after banner, it will become the nightmare for the development of the real economy.

The basic function of financial insurance is to improve the efficiency of resource allocation by the media role of it. In the process of economy development, financial insurance ought to serve the development of the real economy by reducing the cost of resource circulation. However, in the financial activities of acquisition of Vanke by Baoneng, financial insurance funds only flow in the capital market and fail to actually flow to the real economy to realize "turning to virtual economy from the real economy", the status of promoting the expansion and operation of the real economy. Therefore, under the background of the new normal of economy development, how should our enterprises avoid turning to virtual economy from the real economy? How can corporate insurance 
truly promote the growth of the real economy? How to regulate the financing and profit channels of corporate financial insurance? These are the focus of the thesis.

\section{Literature Review}

The relationship between the development of financial insurance industry and economic growth and its influence path are relatively complicated. The existing research mainly focuses on whether there is a relationship between insurance development and economic growth and who is the cause or consequence.

The role of economic growth in promoting the insurance industry has attracted the attention of the academia. The researches of Hakansson (1969), Campbell (1980) [2], Truett Dale \& Truett Lila (1990) [3] and Browne \& Kim (1993) [4] have shown that economic growth has a positive effect on insurance development. Based on the data from 55 developing countries and regions all over the world, Outreville (1990) [5]'s empirical study of relevant cross-section data finds out that for every $1 \%$ increase in GDP, more than 1\% of non-life insurance demand growth will occur. There is a positive correlation relationship between non-life insurance demand and economic growth. Skipper (2009) [6] summarized in detail the literature on the relationship between economic growth and insurance demand, and he believed that economic growth is the most significant influencing factor of insurance demand.

In recent years, domestic scholars have also paid more and more attention to the relationship between insurance development and economic growth. Rao Xiaohui and Zhong Zhengsheng (2005) [7] conducted an empirical test on the dynamic relationship between China economic growth and insurance market development. The conclusion suggests that economic growth is the reason for promoting insurance market development; however, insurance market does not have significant promoting influence on economic growth. Xie Liren (2006) [8] established a economic growth model based on production function, and empirically analyzed the relationship between insurance development and economic growth, finding out that the development of personal insurance has a positive effect on economic growth. Zhou Haizhen (2008) [9] used the data of China to carry out an empirical analysis of the relationship between insurance growth and economic growth. The results indicate that the development of insurance has promoted China's economic growth.

Zhao Shangmei et al. (2009) took the two-sector model as the theoretical starting point and made mathematical analysis and empirical analysis, revealing that every $1 \%$ increase in the insurance industry will drive real GDP growth by $1.22 \%$. Sun Qixiang et al. (2010) [11] conducted an empirical test on penal data of 67 countries from 1995-2007, finding out that the level of a country's insurance development has a significant positive correlation with its degree of market economy development. Zhao Jinwen et al. (2010) [12] carried out an in-depth study on the economic growth effect from national and regional dimensions. They used the nonlinear STR model and the panel data threshold effect model for empirical testing. The results show that current insurance consumption has a significant positive impact on economic growth. Li Xiangyu and Cheng Peng (2012) [13] analyzed in detail the mechanism of insurance on promoting investment. The empirical analysis of 2001-2010 quarterly data suggests that insurance investment will have a positive effect on the economy and investment, no matter long-term or short-term.

The insurance industry belongs to the financial field. Scholars have done many researches on the relationship between financial insurance and the real economy. Hu Xiao (2015) [14]' study suggests that with the continuous development of the virtual economy, the impact of financial insurance on the industrial structure of the real economy is increasing, while its role of promoting the real economy growth is reducing. It will even inhibit the growth of the real economy after a certain level. Based on the panel data of 30 provinces and cities in China from 2006-2015, Yang Xinshun et al. (2017) used the spatial panel data model to demonstrate that there is a significant positive relationship between insurance development and real economic growth, and insurance development shows a significant negative spatial spillover effect. 
The research above expands the analysis space for us to explore how financial insurance can promote the development of the real economy and how to prevent insurance from turning to the virtual economy from the real economy. On this basis, we will further explore the path dependence of financial insurance's promotion of the development of the real economy, and the issues that insurance funds need to pay attention to in the process of promoting the development of the real economy.

\section{The Real Economy Status, Development Dilemma and Reason Analysis}

Since the reform and opening up, China has accumulated enormous real economic wealth and production supply capacity, under the strategy and policy of attaching great importance to the development of the real economy. However, China has experienced a process of "turning to virtual economy from the real economy" since the new century, and the "time lag" between financial tightening and real economy transformation also lead to the stagnation of turning to the real economy from virtual economy. Thus, under the background of new normal economy that the economic growth slows down, how to realize the transformation of real economy from large to strong, how to achieve the transformation of financial funds from virtual economy to real economy are the core issues that China economic development needs to solve.

\subsection{The Important Position of the Real Economy in the Growth of the National Economy.}

The importance of the real economy component, firstly, is reflected in the creation of real wealth for the society, namely the products and service that provide people with practical utility. The degree of ownership of the national real wealth reflects the development level of a country. The wealth accumulated by its own economic development ought to be shared by all the citizens. Secondly, the development of the real economy is a significant channel to provide full employment for the whole people. The increase of most laborers' income in an economic society depends on the real economy, and full employment is the fundamental guarantee for achieving common prosperity for the entire people (Xiang Guocheng et al., 2017) [15]. Hence, economic activities detached from the real economy need to be controlled within a certain economic structure. Otherwise, too much is as bad as too little. It would bring about economic bubble, which will ultimately be against the healthy and sustainable growth of the economy.

\subsection{The Dilemma of the Development of the Real Economy.}

Since the 1980s, the market demand has been shrinking, the excess capacity of the real economy has led to the obvious decline in the rate of return to traditional industrial enterprises real investment. A large amount of financial capital has poured into the high return rate financial and real estate industries. The virtual economy has accelerated its expansion, eventually resulting in the Financialization of the real industries [16].

In this development context, the real economy in China is faced with many difficulties. Firstly, corporate financing channels are narrow, with bank loans being the primary way. Bank loan has always been an important channel for corporate finance in China. As the financial market continues to develop, even though direct financing channels such as stocks and bonds keep enlarging, the threshold is too high. There is still a enormous gap in direct financing for corporate capital demand. Indirect financing still accounts for a large proportion in China's corporate financing structure. Bank loan is still the first choice of enterprises under current financial system. Secondly, corporate credit financing threshold is high. At present, China's economic growth rate is slowing down, and corporate earnings growth is slowing down. The huge risks in the development of credit business force the banks to become more cautious in the process of lending. Thirdly, the structural lean of corporate finance is obvious. Some large enterprises (including state-owned enterprises) not only have enough collateral, but also contribute a lot to the local economy. The local government mainly support them. Therefore, they are the key targets of bank lending, and it is easier for them to obtain bank loans at a lower interest. However, it is difficult for micro, small and medium-sized enterprises to get loan approval because of the bank's consideration of the risk control. 


\subsection{Analysis of the Reasons for the Dilemma of Real Economy Development.}

The four major reasons are as follows: firstly, compared with the current sectors with relatively concentrated funds, the real economy has a small profit margin. Due to the institutional reasons, the industries largely related to the institution such as the real estate industry, financial industry, telecommunication industry are profitable in the long run. The market cannot maintain the profit rate of each industry at a roughly equivalent level through self-regulation. The profit of the real economy is much lower than that of virtual economy industries. According to the statistics, at present, the average profit rate of industrial enterprises above designated size is $5 \%-6 \%$, whereas the return to net assets of financial industry is above $15 \%$. The excessive income gap leads to the separation of production factors and innovative technologies from the real economy to the virtual economy. What should be emphasized here is that the profit-seeking characteristics of financial capital have produced a large number of financial derivatives, making capital circulate in the virtual economy and form a large number of bubbles (Du Yong et al., 2017) [17]. Secondly, the real economy, especially the material production sector is under heavy tax burden. The difficulty of "tax avoidance" is greater than that of other industries. The real economy's huge investment, long return period, slow effect and low liquidity of assets also lead to a decline in corporate investment willingness. Thirdly, there is excess capacity in some real economy industries. Technology is backward and lacks competitiveness, and investment risks are high. According to the statistics of 39 products by the National Development and Reform Commission in 2013, the production utilization rate of 21 products is less than $79 \%$, which belongs to excess capacity. These 21 products are mainly concentrated in traditional manufacturing industries such as steel, cement, rough glass and aluminum. Reducing the supply of funds to such sectors and enterprises is an inevitable choice to achieve the normal operation of the market economy and the balanced allocation of scarce economic resources. Fourthly, due to the special system, banks pursue government projects and abandon the real economy. Since the government has public rights and land, and can obtain the highest credit rating from the bank, domestic commercial banks tend to focus on the government's investment trends and project plans when providing a loan. The government investment projects or government-based investment projects usually get preferential routing in banks. However, the current government invests less in the competitive real economy production sector and instead invests heavily in infrastructure and non-productive public goods. Even though these projects have low return on investment and are even purely consumptive projects with excessive investment, banks are willing to provide loans, due to the join in of the government or the investment of state-owned platforms with government background. The financing of relatively highly efficient production projects (especially private enterprises) is more than difficult. Therefore, formal channel of credit ends up with nothing; private enterprises turn to the private lending market, and capital price is further increasing. This not only reduces the profits of the real economy, but also attracts funds into the private lending market, thereby causing capital to circulate within the virtual economy, which further deteriorating the "hematopoietic function" of financial capital to support the development of the real economy.

To sum up, as a long-term and large-scale capital stock of financial insurance enterprises, insurance funds ought to provide risk guarantee for the real economy (especially small and mediumsized real economy manufacturing enterprises), and "blood transfusion" for the real economy component in the capital market. It should also help small and medium-sized real economy enterprises to successfully solve the problem of financing difficulties, thus vitalizing the real economy manufacturing industries.

\section{The Path Dependence of Financial Insurance Promotion on the Real Economy}

In the future period, China's economic operation will be in a new normal state. The main themes are deepening reform, accelerating innovation, economic transformation, structural adjustment, mode transformation, and industrial upgrading. Insurance funds should be adept in seizing opportunities and catching up with the country's reform. It also ought to make a due contribution to the realization 
of "turning to the real economy from the virtual economy" and then to the achievement of the great "China Dream". In this regard, we need to clarify the path dependence of financial insurance on the real economy.

From the perspective of the insurance business, the premium income in 2016 reached 3.1 trillion yuan. In 2017, the premium income is expected to reach 3.5 trillion yuan, and the industry enjoys sound momentum. From the perspective of the use of insurance funds, the development of the real economy is mainly supported via three channels. First, indirect financing of the real economy through transforming bank deposits into bank loans. Up to the end of August 2017, insurance institutions had more than 1.96 trillion-yuan bank deposits, most of which were long-term agreement deposits and fixed-term deposits, becoming an important source of funds for medium and long-term loans of commercial banks. Second, direct financing of the real economy through the purchase of financial instruments such as bonds and stocks. Up to the end of August 2017, insurance funds invested in bonds, stocks and securities investment funds added up to more than 6.92 trillion yuan. Third, financing the real economy projects through the equity, debt, funds and other means. Up to the end of June 2017, insurance funds invested more than 4 trillion yuan in the real economy through debt investment plans, equity investment plans, asset support plans, industrial funds, trust plans, and private equity funds, etc. In particular, insurance funds have made positive contributions in supporting the implementation of national strategies. Up to the end of August 2017, only in the aspect of project financing, the investment "One Belt and One Road Initiative" was 74.14 billion yuan; the investment in green finance was 605.4 billion yuan; the investment in the Yangtze River Economic Belt was 264.6 billion yuan; the investment in shantytowns transformation was 124.1 billion yuan; the investment of the coordinated development of in Beijing-Tianjin-Hebei was 118.4 billion yuan; the investment in revitalizing the old industrial base in Northeast China was 30 billion yuan. Therefore, insurance funds become the discoverers, leaders and creators of value in the serve of the real economy. It also becomes an important force that supports the development of the real economy.

Therefore, the path dependence of insurance funds promotion on the real economy is the premise and basis for our reasonable control and formulation of supervision and execution rules, and is also the fundamental starting point for advancing policy advice.

\section{Conclusions and Risk Prevention Recommendations}

Real economy is regarded as an important part of the development of the national economy in the thesis via analysis. It is the main channel of creating real wealth for the society, realizing full employment and promoting economic growth. However, in the current reality economic development background "turning to the virtual economy from the real economy", the real economy is facing a series of "financing difficulties". In this regard, we have deeply analyzed the reasons for its development dilemma, and believe that insurance funds, as a long-term and large-scale capital stock, is of benefit to provide risk guarantees for the real economy (especially small and medium-sized real economy manufacturing enterprises) and provide "blood transfusion" for the real economy component in the capital market, etc. Finally, we have deeply discussed the three major path dependence of insurance funds promotion on the development of the real economy, which provides a benchmark for the potential risk prevention of insurance capital to boom the healthy development of the real economy.

Currently, the financial insurance industry is keen to make short-term speculation in the capital market. Aiming to raise a large number of funds for the banner acquisition of listed companies, insurance companies use a small number of their own funds plus a large amount of borrowing leverage funds to increase their holdings in the capital market, which does not only easily lead to cross-risk, disrupt the normal operation of the capital market, and the use of insurance funds has a time limit and a cost-benefit double mismatch problem. The inherent high risk is likely to cause a large number of policy holders to suffer from economic income loss. Therefore, specific risk prevention recommendations are as follows: 
From the perspective of insurance supervision, insurance should return to the essence of diversified risks. First, on the debt side, the minimum guarantee period of insurance products should be extended appropriately, in order to prevent some insurance companies from rolling out short-term high-priced products, resulting in term mismatches of the insurance funds and bringing about liquidity risk. Second, the responsibilities of chief actuaries and senior managers of insurance companies ought to be strengthened. Intensity penalties and increase the cost of illegal activities. Impose penalties on illegal insurance companies in a timely manner. Third, on the asset side, strengthen the matching of assets and liabilities; encourage long-term shareholding, and provide preferential policies for longterm value investment of insurance institutions; promptly provide window guide of the behavior of short-term investing in stocks, and suspend its stock investment ability if necessary.

From the perspective of security supervision, it is essential to refine the regulatory rules for listed companies with banner acquisition. Set the "double proportion threshold limit" for stock investment of insurance funds. At present, the regulation only stipulates the proportion of the total assets at the end of the last quarter that the stock investment accounts for. There is no appropriate restriction on the proportion of shares of listed company held by the insurance funds. However, the development of China's insurance institutions' operating regulations and systems is still far from mature, requiring more allocation of fixed-income assets, and the allocation of stock-based high-risk assets can only be gradually increased. In addition, the development of China's stock market is not mature, and the management of listed companies lacks the experience of communicating with institutional investors such as insurance funds, which is likely to cause conflicts. As a result, at this stage, it is necessary to set the upper limit of the proportion of insurance funds holding shares of listed companies, so that the insurance funds can smoothly enter the stock market operation, and then gradually liberalize it when the insurance and stock markets become mature.

Strengthen the information disclosure obligations of insurance funds. First, information disclosure of insurance company governance should be strengthened. Insurance companies are supposed to be able to independently conduct risk analysis and investment decisions to prevent manipulation by major shareholders or actual controllers. Therefore, the regulators should require the insurance company shareholders to disclose information such as sources of investment, related transactions with insurance companies, and control relationships with other shareholders to prevent insurance companies from becoming a financing platform for major shareholders. Second, strengthen the information disclosure of shares in secondary market of insurance companies. The insurance company that hold more than $5 \%$ of the shares of a listed company shall fulfill its information disclosure obligations, and it shall fulfill its information disclosure obligations for each increase or decrease of $5 \%$ of the shares. Third, the insurance funds own the advantages of scale, capital and information, which has a greater impact on the stock market. Information should be disclosed such as the person acting in concert, the source of funds, the balance of funds used in the insurance fund account, and the holding period.

Establish penetrating regulatory rules for insurance funds with banner. Insurance funds use a variety of financial derivatives in listed companies with banner acquisition, from insurance, banking, trusts, brokerages and other channels of funds. In the context of separate operations and supervision, the supervision scope of the China Insurance Regulatory Commission is limited to the solvency, assets and liabilities and corporate governance of insurance institutions. The supervision scope of the China Securities Regulatory Commission is limited to determining whether insurance funds and other entities are persons acting in concert. The supervision scope of the China Banking Regulatory Commission is limited to determining whether bank borrowings are used by insurance companies as listed companies with banner acquisition. However, there may accumulate a large number of risks in the three-way intersection area or gray area. The failure of regulatory coordination exposed in the 2015 stock market crash has fully proved this point. Therefore, penetrating regulatory rules should be established to regulate cross-market and inter-agency capital business operations to ensure the rational use of insurance funds. 


\section{References}

[1]. Hakansson N. H. Optimal Investment and Consumption Strategies Under Risk, An Uncertain Lifetime, and Insurance[J]. International Economic Review, 1969, 10(3): 443-466.

[2]. Campbell R. A. The Demand for life Insurance: An Application of The Economics of Uncertainty[J]. Journal of Finance, 1980, 35(5): 1155-1172.

[3]. Truett D. B., Truett L. J. The Demand for Life Insurance in Mexico and the United States: A Comparative Study[J]. Journal of Risk\& Insurance, 1990, 57(2): 321-328.

[4]. Browne M. J., Kim K. An International Analysis of Life Insurance Demand[J]. Journal of Risk\& Insurance, 1993, 60(4): 616-634.

[5]. Outreville J. F. The Economic Significance of Insurance Markets in Developing Countries[J]. Journal of Risk\& Insurance, 1990, 57(3): 487-498.

[6]. Skipper H. D., Barfield C. E. Insurance in the General Agreement on Trade in Services[J]. Journal of Risk\& Insurance, 2009, 23(5): 213-217.

[7]. Rao Xiaohui, Zhong Zhengsheng. Can Insurance Promote Economic Growth: An Empirical Analysis Based on China[J]. Shanghai Economic Research, 2005, (12): 14-20.

[8]. Xie Liren. An Empirical Analysis of the Relationship between Insurance Development and Economic Growth[J]. Seeker, 2006, (8):45-47.

[9]. Zhou Haizhen. Research on the Relationship between the Development of Insurance Industry and the Promotion of Economic Growth [J]. Management World, 2008, (11): 170-172.

[10]. Zhao Shangmei, Li Yong, Pang Yufeng. Theoretical Model and Empirical Test of the Contribution of Insurance Industry to Economic Growth[J]. Insurance Research, 2009, (1): 5156 .

[11]. Sun Qixiang, et al. The Effects of Market Economy on the Development of Insurance Industry: Theoretical Analysis and Empirical Evidence [J]. Financial Research, 2010, (2): 158172.

[12]. Zhao Jinwen, Xing Tiancai, Xiong Lei. The Economic Growth Effect of China's Insurance Consumption[J]. Economic Research, 2010, (Supplement): 39-50.

[13]. Li Xiangyu, Cheng Peng. Research on the Contribution of Insurance Funds to Investment and Economic Growth[J]. Insurance Research, 2012, (9): 56-63.

[14]. Hu Xiao. The Impact of Virtual Economic Development on the Real Economy: Growth or Structural Adjustment[J]. Finance and Economics, 2015, (2): 52-62.

[15]. Xiang Guocheng, Chen Tingying, Zhong Shihu, et al. Division of labor, Balance of Power and Common Prosperity [J]. World Economic Papers, 2017, (5): 40-54.

[16]. The definition of Krippner (2005) is widely accepted. He believes that financialization means that "the acquisition of profits is mainly through financial channels rather than trade and commodity production". See: Krippner G R. The Financialization of the American economy [J]. Socio-Economic Review, 2005, 3(2): 173-208.

[17]. Du Yong, Zhang Huan, Chen Jianying. The Impact of Financialization on the Future Main Business Development of Entity Enterprises: Promotion or Suppression[J]. China Industrial Economy, 2017, (12): 113-131. 